\title{
Unexpected endometrial malacoplakia related to abortion and placental rests retention: a case report
}

\author{
Antonio d'Amati ${ }^{*}$ (D, Emilio Bellitti and Leonardo Resta
}

\begin{abstract}

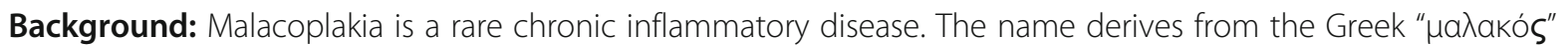
meaning "soft" and " $\pi \lambda a ́ \xi "$ meaning "plaque", describing its usual macroscopic presentation as a friable yellow soft plaque. It was first described by von Hansemann in 1901 and by Michaelis and Gutmann in 1902. The urinary system is the most commonly involved site. Female genital tract involvement is extremely rare. Treatment is prevalently based on antibiotics with surgical intervention sometimes necessary. Prognosis is usually good, but relapse may frequently occur.

Case presentation: This report illustrates the first case of endometrial malacoplakia in a 40 years-old patient who received endometrial curettage due to the retention of placental rests following an abortion. After conspicuous vaginal sero-hematic secretions, the patient received a further curettage. The histological examination did not show any retention of chorionic rests, but an endometrial and myometrial infiltration of histiocytes with large granular cytoplasm within a chronic inflammatory background. Immunoreactivity for CK-pool was negative, while CD68 immunostaining was strongly positive.

Conclusions: Malacoplakia of endometrium is an extremely rare condition, with few cases reported in the whole international literature. In this paper, we present the first case associated to an abortion followed by endometrial curettage procedures. This rare disease should always be attentively examined, considering, among differential diagnoses, uterine neoplasms or physiological conditions such as cumulus of foamy macrophages in the endometrium.
\end{abstract}

Keywords: Pathology, Malacoplakia, Endometrial diseases, Abortion, Case report

\section{Background}

Malacoplakia is a rare chronic inflammatory disease, with a mean age at diagnosis of 50 years old and a female to male ratio of $4: 1$. It occurs more frequently in patients with immunodeficiency conditions. The disease was first described by von Hansemann in 1901 and by Michaelis and Gutmann in 1902. The name malacoplakia derives from the Greek words " $\mu \alpha \lambda \alpha \kappa o$ c", which

\footnotetext{
* Correspondence: damatiantonio@yahoo.it; leonardo.resta@uniba.it Section of Pathology, D.E.T.O. (Department of Emergency and Organ Transplantation), University of Bari, Piazza Giulio Cesare 11, 70124 Bari, BA, Italy
}

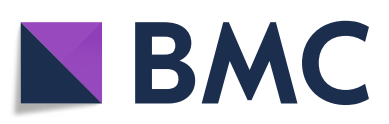

means soft, and " $\pi \lambda \dot{\alpha} \xi$ ", meaning plaque, and is related to its macroscopic appearance: soft and friable yellow plaques or, more rarely, nodules or masses. Histologically, it is characterized by a mixed inflammatory infiltrate, composed of lymphocytes, plasma cells, neutrophils and aggregates of hystiocytes with abundant granular eosinophilic cytoplasm, known as von Hansemann cells. The genitourinary tract is the most common involved site, followed by the gastrointestinal tract, but any site of the human body may be affected. The female genital tract is a very rare localization, with only few cases reported in literature, involving vagina, uterus,

(c) The Author(s). 2020 Open Access This article is licensed under a Creative Commons Attribution 4.0 International License, which permits use, sharing, adaptation, distribution and reproduction in any medium or format, as long as you give appropriate credit to the original author(s) and the source, provide a link to the Creative Commons licence, and indicate if changes were made. The images or other third party material in this article are included in the article's Creative Commons licence, unless indicated otherwise in a credit line to the material. If material is not included in the article's Creative Commons licence and your intended use is not permitted by statutory regulation or exceeds the permitted use, you will need to obtain permission directly from the copyright holder. To view a copy of this licence, visit http://creativecommons.org/licenses/by/4.0/ The Creative Commons Public Domain Dedication waiver (http://creativecommons.org/publicdomain/zero/1.0/) applies to the data made available in this article, unless otherwise stated in a credit line to the data. 
fallopian tubes and ovary. The most common presentation of endometrial malacoplakia is post-menopausal bleeding. We report herein the first case of endometrial malacoplakia associated to an abortion followed by uterine curettage procedures.

\section{Case presentation}

A 40-year-old female patient was admitted to our hospital for conspicuous vaginal sero-hematic secretions. Anamnestic information asserted that the patient previously received three endometrial curettage after a surgical abortion procedure. Histological examination after each endometrial curettage showed regression of chorionic villi and decidualization of the endometrium and the diagnosis of placental rests retention was made. After being admitted for conspicuous vaginal serohematic secretions, the patient received a further curettage in order to assess the possible retention of placental rests. The histological evaluation did not show any retention of chorionic rests, but demonstrated an endometrial and myometrial diffuse chronic inflammatory infiltration, with an extensive background of hyaline stroma. The inflammatory infiltrate showed a variegate composition, being made of lymphocytes, plasma cells and occasional polymorphonuclear leukocytes, but the majority of the cellular elements was represented by histiocytes with abundant granular cytoplasm and basophilic inclusions, morphologically relatable to the so called von Hansemann cells (Fig. 1). Periodic acid-schiff (PAS) reaction highlighted a diffuse cytoplasmic staining in von Hansemann cells (Fig. 2). The immunohistochemical analysis revealed that those elements were strongly positive for CD68 (Fig. 3) and negative for CKpool (Fig. 4). On the basis of morphological, histochemical and immunophenotypical evidence, the histological

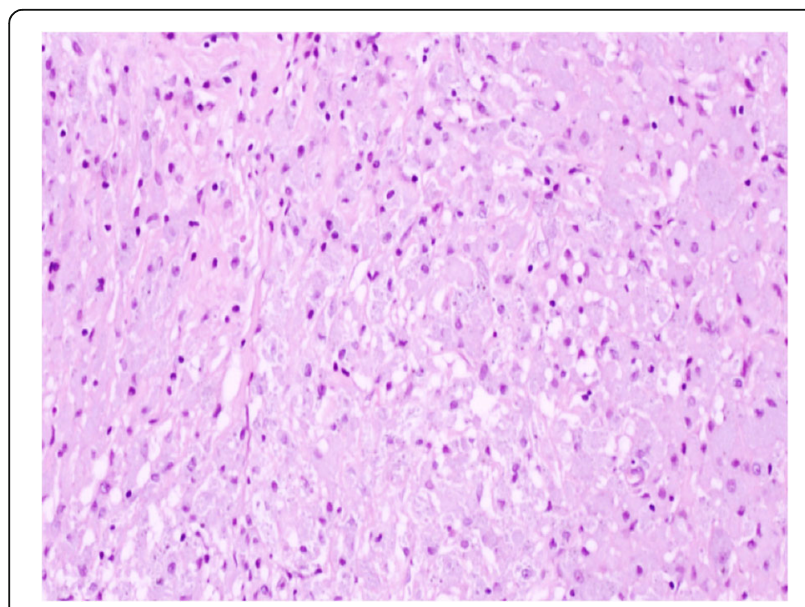

Fig. 1 Chronic inflammatory infiltrate, mostly composed of histiocytes with abundant granular cytoplasm and basophilic bodies. (H\&E stain, 100x)

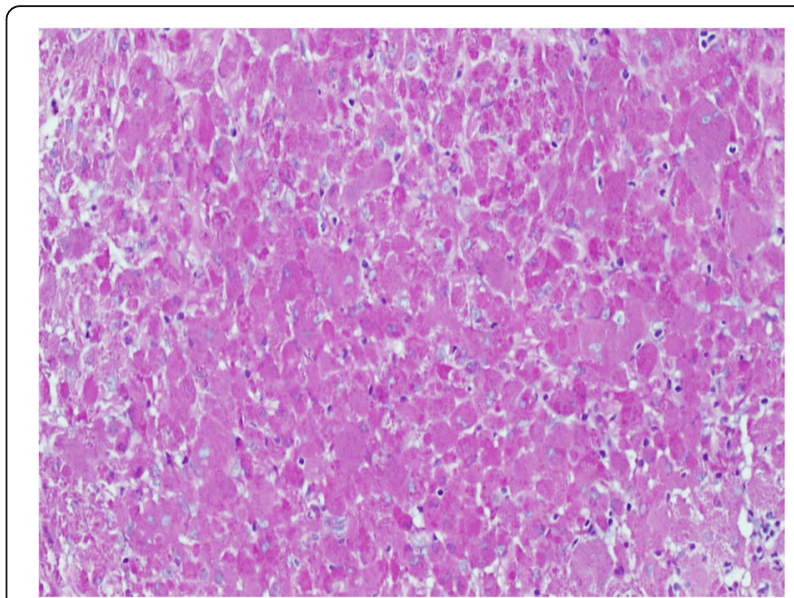

Fig. 2 Diffuse cytoplasmic staining in histiocytic elements. (Periodic acid-Schiff stain, 100x)

diagnosis of malacoplakia was made, excluding uterine neoplasms and other differential diagnoses. In the following months, due to relapse of clinical manifestations, nonetheless administration of antibiotic drugs, the patient underwent two further uterine curettage, with the diagnosis of recurrent endometrial malacoplakia.

\section{Discussion and conclusions}

Endometrial malacoplakia is an extremely rare condition, as demonstrated by the paucity of cases reported in the international literature. The etiopathogenesis of the disease is far from being completely understood, but recent evidence agrees with the presence of defective macrophage phagolysosomal activity [1]. Several studies reported a correlation between malacoplakia and immunodeficiency conditions, such as primary immunodeficiency, steroid administration, AIDS and diabetes [2]. The defect in the phagolysosomal activity is believed

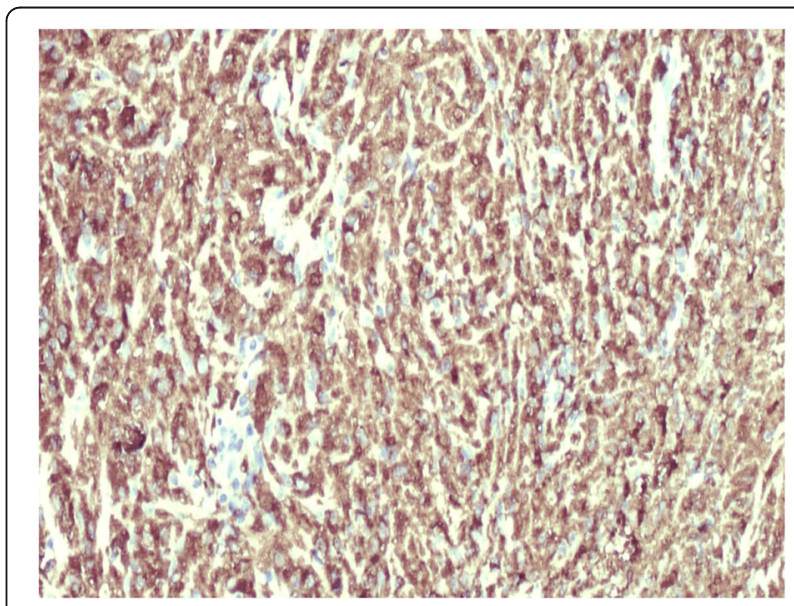

Fig. 3 Strong cytoplasmic positivity for CD68, highlighting several histiocytes. (100x) 


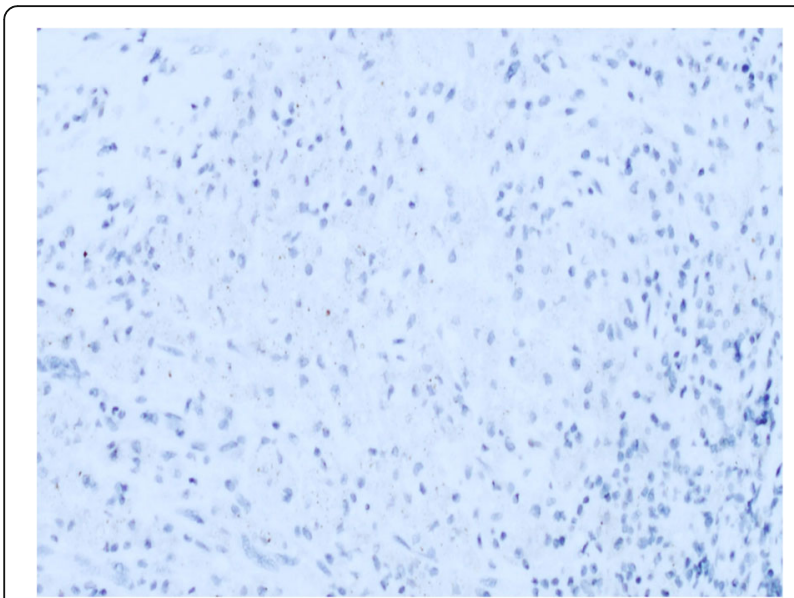

Fig. 4 Negative immunoreaction for CK-pool. (100x)

to be a consequence of immunodeficiency, leading to incomplete bacterial digestion and to Michaelis-Gutmann bodies formation. These bodies are considered as a pathognomonic microscopical sign of malacoplakia, but they are not strictly necessary for the diagnosis, as they may not be seen in early stages of the disease. The case presented in this report developed endometrial malacoplakia after an abortion and subsequent uterine curettage due to retention of placental rests. On the basis of the clinical history, we might suppose a bacterial contamination leading to the development of the disease, but in the absence of a known condition of immunodeficiency. Moreover, due to placental rests retention, we might hypothesize a role played by trophoblast. In fact, cytokines released by trophoblast cells have been reported to be involved, among various functions, in immunoregulation and maternal-fetal tolerance during pregnancy $[3,4]$. The clinical presentation of endometrial malacoplakia is characterized by post-menopausal bleeding, abnormal uterine bleeding in a menstruating woman or suspicious uterine mass [5-7]. Our patient presented with abundant vaginal sero-hematic secretions and received a further curettage, in order to establish a possible placental rests retention, but the histological examination revealed the microscopical features of endometrial malacoplakia and the absence of chorionic rests. Due to its clinical presentation and endoscopical appearance, uterine malacoplakia requires a careful differential diagnosis, in order to rule out other inflammatory processes and uterine neoplasms. The therapeutic approach to malacoplakia is based on surgical and medical options, but there are no established guidelines. Surgical intervention varies in accordance to site and extension of the disease. Antibiotic therapy is prevalently based on drugs capable of reaching high concentrations inside macrophages, such as quinolones or trimethoprim-sulfamethoxazole $[8,9]$. Currently, antibiotics, combined with surgery, provide the best therapeutic protocol. A novel protocol, including antibiotics, bethanechol and ascorbic acid, has been recently used in the treatment of cerebral malacoplakia [10]. In the case herein reported the patient was treated with uterine curettage, combined with quinolones antibiotic therapy, obtaining a rapid clinical improvement, with satisfactory disappearance of symptoms, as also reported by the patient. Even though management of this rare condition is very challenging, the prognosis is commonly good. Nevertheless, recurrence, as in the case we reported herein, and complications may frequently occur throughout the years.

\section{Acknowledgements \\ Not applicable.}

Authors' contributions

All authors contributed equally, read and approved the final manuscript.

Funding

Not applicable.

Availability of data and materials

Not applicable.

Ethics approval and consent to participate

Not applicable.

Consent for publication

Obtained.

\section{Competing interests}

The authors declare that they have no competing interests.

Received: 25 May 2020 Accepted: 14 July 2020

Published online: 18 July 2020

\section{References}

1. Jung YS, Chung DY, Kim EJ, Cho NH. Ultrastructural evidence of the evolutional process in malakoplakia. Histol Histopathol. 2020;35(2):177-84.

2. Biggar WD, Keating A, Bear RA. Malakoplakia: evidence for an acquired disease secondary to immunosuppression. Transplantation. 1981;31(2):109-12.

3. Liu J, Hao S, Chen X, Zhao H, Du L, Ren H, et al. Human placental trophoblast cells contribute to maternal-fetal tolerance through expressing IL-35 and mediating iTR35 conversion. Nat Commun. 2019;10(1):4601.

4. Naruse K, Innes BA, Bulmer JN, Robson SC, Searle RF, Lash GE. Secretion of cytokines by villous cytotrophoblast and extravillous trophoblast in the first trimester of human pregnancy. J Reprod Immunol. 2010;86(2):148-50.

5. Chadha S, Vuzevski VD, ten Kate FJ. Malakoplakia of the endometrium: a rare cause of postmenopausal bleeding. Eur J Obstet Gynecol Reprod Biol. 1985;20(3):181-9.

6. Chalvardjian A, Picard L, Shaw R, Davey R, Cairns JD. Malacoplakia of the female genital tract. Am J Obstet Gynecol. 1980;138(4):391-4.

7. Sonowal C, Kalita P, Das A, Rabha H, Saikia A. Malakoplakia of the uterus: a rare cause of postmenopausal bleeding mimicking malignancy. J Clin Diagn Res. 2019;13(8):QD01-3.

8. van der Voort HJ, ten Velden JA, Wassenaar RP, Silberbusch J. Malacoplakia. Two case reports and a comparison of treatment modalities based on a literature review. Arch Intern Med. 1996;156(5):577-83.

9. Christensen M, Knuhtsen S, Knudsen E. Colonic malacoplakia treated with sulfamethizole and trimethoprim. Ugeskr Laeger. 2011;173(7):509-10.

10. Fudaba H, Ooba H, Abe T, Kamida T, Wakabayashi Y, Nagatomi H, et al. An adult case of cerebral malakoplakia successfully cured by treatment with antibiotics, bethanechol and ascorbic acid. J Neurol Sci. 2014;342(1-2):192-6.

\section{Publisher's Note}

Springer Nature remains neutral with regard to jurisdictional claims in published maps and institutional affiliations. 